\title{
Pascal Blanchard, Gilles Boëtsch, Dominique Cheve (dir.), Corps \& couleurs
}

Paris, CNRS, 2008, 227 p.

\section{Eugénie Briot}

\section{(2) OpenEdition}

\section{Journals}

Édition électronique

URL : http://journals.openedition.org/dht/1606

DOI : 10.4000/dht.1606

ISSN : $1775-4194$

Éditeur :

Centre d'histoire des techniques et de l'environnement du Cnam (CDHTE-Cnam), Société des élèves du CDHTE-Cnam

\section{Édition imprimée}

Date de publication : 1 décembre 2011

Pagination : 224-225

ISBN : 978-2-9530779-7-1

ISSN : 0417-8726

\section{Référence électronique}

Eugénie Briot, «Pascal Blanchard, Gilles Boëtsch, Dominique Cheve (dir.), Corps \& couleurs »,

Documents pour l'histoire des techniques [En ligne], 20 | 2e semestre 2011, mis en ligne le 13 septembre 2012, consulté le 24 septembre 2020. URL : http://journals.openedition.org/dht/1606 ; DOI : https:// doi.org/10.4000/dht.1606

Ce document a été généré automatiquement le 24 septembre 2020

(c) Tous droits réservés 


\section{Pascal Blanchard, Gilles Boëtsch, Dominique Cheve (dir.), Corps \& couleurs}

Paris, CNRS, 2008, 227 p.

\section{Eugénie Briot}

\section{RÉFÉRENCE}

Pascal Blanchard, Gilles Boëtsch, Dominique Cheve (dir.), Corps \& couleurs, Paris, CNRS, 2008, $227 \mathrm{p}$. 
1 Faisant pendant à l'ouvrage Coloris Corpus, paru en 2008 aux Éditions du CNRS, regroupant sous la direction des mêmes auteurs une quarantaine d'articles, corps et couleurs paru la même année, également aux Éditions du CNRS, sous la conduite de Pascal Blanchard, Gilles Boëtsch et Dominique Chevé, aborde sous la forme d'un ouvrage de grand format, richement illustré, et d'une vingtaine de contributions plus ramassées, l'«identité dans tous ses éclats ».

2 Trois angles thématiques ont été retenus

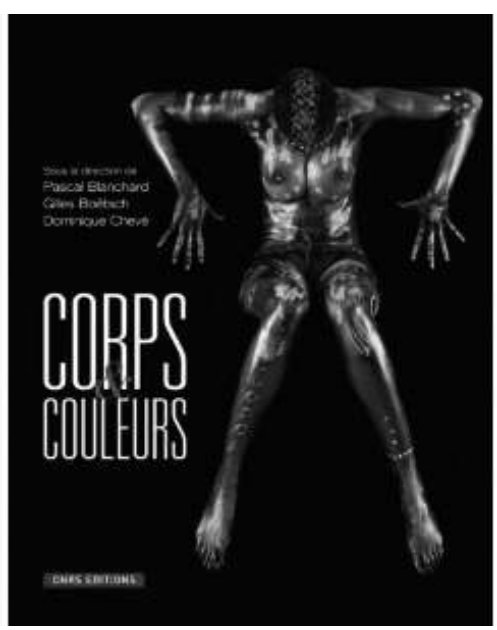
pour cerner ce sujet : «États », « Pratiques

» et «Signes ", dont les intitulés structurent l'ouvrage. Chacune de ces trois parties regroupe elle-même six articles : "États » se décline ainsi en «La peau », "La chair », «Les affections », « Le sexe », « La mort » et « Le métissage »; « Pratiques » s'articule autour de contributions intitulées "Le plaisir », «Les violences », "L'effort ", "Le sacrifice », « Le rituel » et «L'hybride »; et « Signes » regroupe des thèmes tels que « La beauté », «Les stigmates », "Le genre », "L'identité », «La domination » et «La publicité ».

3 Si la majorité des auteurs sont anthropologues (Jean-Pierre Albert, Gilles Boëtsch (qui est anthropobiologiste), Dominique Chévé, Hélène Claudot-Hawad, Antonio Guerci, Philippe Liotard, David Le Breton) ou historiens (Nicolas Bancel, Pascal Blanchard, Georges Vigarello), d'autres sont historiens d'art (Farid Abdelouahad, Bernard Lafargue), Bernard Andrieu est philosophe, Frédéric Baillette responsable de la publication de la revue Quasimodo, Fabien Coutarel ergonome, Régine Detambel kinésithérapeute et conférencière, Pascal Hintermeyer sociologue, et Elisabeth TissierDesbordes professeur de marketing. Le choix de la diversité est posé d'emblée: privilégiant tant «les logiques du sensible et de l'imaginaire, nécessairement empreintes de subjectivité » (p. 10) que «les logiques des discours idéologiques et classificatoires, ceux des pouvoirs bio-médicaux, commerciaux, politiques, coloniaux, etc. » (p. 13), la latitude d'approche envisagée pour traiter chaque sujet se révèle extrêmement libre. C'est donc sous l'angle de disciplines différentes, et en croisant leurs regards complémentaires, que les auteurs abordent tour à tour l'un des dix-huit thèmes posés par l'ouvrage, en faisant valoir leur approche de spécialistes, mais aussi en circonscrivant le sujet de façon nécessairement partielle, que la relative brièveté des articles rend certes non exhaustive, mais aussi ouverte.

De ces lectures courtes, au prisme d'une discipline, émergent des réflexions fécondes : «Le plaisir » envisagé à la lumière de l'art du XVIII ${ }^{e}$ siècle sous la plume de Farid Abdelouahab, ou « Le sacrifice » étudié par Jean-Pierre Albert à l'aune des paradoxes de la pensée chrétienne, comptent par exemple parmi les très belles pages de l'ouvrage. A contrario, une contribution comme celle de Frédéric Baillette, intitulée « Les violences ", pèche par son manichéisme. S'il s'agit d'évoquer la guerre, peut-on pour autant écrire que « La volonté d'infliger un maximum de pertes à l'adversaire, surtout lorsqu'il fait figure de voyou, stimule toujours les militaires. [...] Le camp des perdants doit être jonché de cadavres, ramené à l'âge de pierre »? C'est négliger qu'il existe aujourd'hui 
un Droit des conflits armés, appliqué par un certain nombre de pays. Une contextualisation plus stricte aurait été souhaitable.

5 Au-delà des textes, le format de l'ouvrage, qui relève de la catégorie du « beau livre », donne toute sa place à une iconographie dense et extrêmement riche, contribuant beaucoup à l'originalité de l'ensemble. Le choix iconographique, qui mêle peintures, gravures, cartes postales, publicités, affiches, photographies anciennes et contemporaines, présente cependant un certain nombre d'illustrations dont la violence, la crudité, font question. Qu'il s'agisse de photographies de presse (par exemple : Hurein, Pendaison publique à Téhéran, 2007 ; Agence Sipa, Scène de violence au Kenya, 2007), ou de photographies artistiques (Jeffrey Silverstone, Femme morte dans son sommeil, morgue des Etats-Unis, 1972), leur présence au cœur de l'ouvrage relève d'une volonté délibérée de montrer même l'insupportable, et d'exposer le lecteur, en le confrontant à des scènes dures ou choquantes. Ce parti-pris, qui présente certainement l'intérêt de bannir toute complaisance, et de ne pas occulter une facette de la réalité telle qu'elle existe, fait cependant de l'ouvrage, en certains passages, une lecture émotionnellement exigeante, requérant du lecteur qu'il accepte à son tour une confrontation à la violence des choses, et un renoncement à se voiler la face.

6 Sur le strict plan formel, l'ouvrage, qui comporte un certain nombre de coquilles, a certainement souffert d'un manque de relectures. Pour autant, servi par une iconographie dense et d'une grande richesse, parfois exigeante et sans complaisance, il demeure une lecture extrêmement stimulante.

\section{AUTEURS}

\section{EUGÉNIE BRIOT}

IRG, Université Paris-Est -Marne-la-Vallée 